structural chemistry. It is, as far as I know, the first text to give a detailed account of methods of constructing different types of molecular models and their application to the understanding of various chemical structures. After a brief introduction to the basis of chemical topology, the second part of the book is cast in the form of problems and constructions with the different types of models, and the third part essentially provides help with, and answers to, these exercises. The first chapter of part two is an account of the construction of the regular and other polyhedra using multiple connectors and rods. The second chapter deals with the use of drilled balls and spokes to build up two and three dimensional nets representing chemical structures. The third treats the packing together of spheres in contact, covering both the conventional closepacking situations and the packing together of sets of spheres of different sizes. I found this chapter particularly helpful and informative; most of the material in it could well be incorporated into an experimental course for first or second year chemists. Chapter four gives an account, through problems, of structures built up from tetrahedra sharing one or more verticals, and chapter five deals in the same way with octahedra. Chapter six contains studies on miscellaneous structures, built largely from octahedra and tetrahedra together.

It is difficult to assess all the modelbuilding exercises without the accompanying model-building kit, which, at $£ 25$, seems very costly-chiefly, perhaps, because of the expensive models in 'Perspex' of tetrahedra and octahedra. At present the book must be regarded as an adjunct of the expensive model-building set, which is a pity. The inclusion of a chapter for students on how to build, and where to buy, inexpensive components from which to build models would greatly increase the appeal of this volume. $\quad$ T. C. WADDINGTON

\section{Raman Spectra Revitalized}

Laser Raman Spectroscopy. By T. R. Gilson and P. J. Hendra. Pp. xiv +266. (Wiley (Interscience) : London and New York, July 1970.) 90s.

A FEW years ago, laser physics was an esoteric branch of physical science, frequently overcredited by its initiates with the facility to provide solutions for all manner of experimental problems. The days when every physical laboratory had to have its expensive and temperamental laser system for prestige purposes have now passed; inexpensive and docile lasers are used instead for a variety of "workhorse" jobs. This drift out of the spotlight and into the corps-de-ballet is reflected in the appearance of a number of books dealing in detail with the application of laser systems to specific physical techniques.

The Raman effect, the inelastic scattering of light by matter, was discovered in the 1930s and was used in the elucidation of atomic and molecular structure. Experimentally, however, high intensity monochromatic light sources were needed which were at that time very difficult to produce. This limitation meant that Raman spectroscopy fell into neglect in the 1940s. The advent of the laser provided an ideal high intensity source and set the stage for a renaissance of the technique.

Gilson and Hendra's book is, to some extent, an avowed academic publicity campaign for this renaissance. Written in a breezy style, the book introduces the reader briefly to Raman scattering and to lasers, describes current commercial systems, then gives a detailed description of the analysis of Raman spectra for various states of matter. The success of the book depends on two criteria. First, the practical details must not date too rapidly. Second, the techniques which laser Raman spectroscopy is likely to replace must be reaching the limit of development. The sections dealing with laser systems are unlikely to date quickly, especially as the authors have considered possible future developments. The experimental techniques described are varied and it seems unlikely that, barring a conceptual breakthrough, their range will be superseded in the near future.

The answer to the second question is still open, but Gilson and Hendra have written a readable and thorough introduction to laser Raman spectroscopy which can be recommended to all lay physicists and chemists interested in this technique.

D. G. C. Jones

\section{Mechanics of Memory}

Biology of Memory. Edited by Karl $\mathrm{H}$. Pribram and Donald E. Broadbent. Pp. $x+323$. (Academic: New York and London, September 1970.) 107s.

NoBODY could regard memory as an under-reviewed topic in the past few years. Indeed, in spite of the fact that it has become a bandwagon research area, since 1960 there have probably been more review volumes and symposia published than really original papers. But with the neurobiologist Pribram and the psychologist Broadbent editing this book, I felt entitled to expect something worthwhile. The first disappointment is to discover that a large proportion of the papers (we are not told which) were in fact given at the Moscow Psychology Congress as long ago as 1966, and most of the rest, apparently, at a meeting in Washington in 1967. In spite of the delay, they have not been brought up to date; several contain no references beyond 1965 and use words such as "recent" in describing work done in 1963 and 1964. Whether editors or publishers are to blame, there is no excuse for foisting off this collection as an up to date set of reviews. The second disappointment is to discover that a number of the papers are in fact little more than abstracts a couple of pages in length, which cannot do justice to the complexity of the issues or to the contributions of individual workers. If one packs thirty-three authors into such a small number of pages, brevity perhaps becomes inevitable, but the disproportion between Melton's three page review of the vexed issue of the relationship between shortand long-term memory, and thirty pages of inconsequentially detailed description of McConnell's attempts to transfer responses between animals by injections of RNA (a theme reviewed much more comprehensively recently in a volume edited by Byrne), is striking and invidious.

This having been said, there are certainly good things in the book. It is still so difficult to get access in English to reviews of Russian work that the substantial contribution to this book by Soviet scientists is welcome. The studies of Sokolov on habituation in a molluscan giant neurone are of general importance, and the remarkable observation by Vinogradova and her colleagues, that there are in the hippocampus a whole variety of cells which respond in different ways to repetition and novelty of stimulus, including, apparently, some cells which can actually "count" trains of stimuli and register changes in their number, is bound to play a major part in future attempts to build models of memory mechanisms. It is also intriguing to learn, if only for students of acronyms, that a computer simulation of a brain memory mechanism devised by Spinelli at Stamford rejoices in the name of OCCAM, not, so far as I can tell, as a tribute to the razor-wielder of philosophical repute, but derived from OmniumGatherum Core Content Addressable Memory.

In the preface to this collection, the editors tell us that "as recently as in midcentury, biologists and psychologists alike despaired of coming to grips with the problem of how we organize our experience into the lasting structures that influence subsequent behaviour. The scientific climate has changed radically during the 1960s; a frontal attack on the problem of memory organization has been mounted".

Well, yes; and repulsed, in large measure, with a good number of assault troops injured in the conflict. We now know it is likely to be a long siege rather than a swift assault. It is a pity that this book neither gives us the excitement of the frontal attack of the 1960s, nor lays the strategy for the siege of the 1970s.

STEVEN Rose 